\title{
Micro-plate tectonics and kinematics in Northeast Asia inferred from a dense set of GPS observations
}

\author{
Shuanggen Jin ${ }^{\mathrm{a}, \mathrm{b}, *}$, Pil-Ho Park ${ }^{\mathrm{b}}$, Wenyao Zhu ${ }^{\mathrm{a}}$ \\ a Shanghai Astronomical Observatory, Chinese Academy of Sciences, Shanghai 200030, China \\ b Space Geodesy Division, Korea Astronomy and Space Science Institute, Daejeon 305-348, South Korea
}

Received 27 November 2006; received in revised form 6 March 2007; accepted 6 March 2007

Available online 14 March 2007

Editor: C.P. Jaupart

\begin{abstract}
The plate tectonics of Northeast Asia are very complex with diffuse and sparse seismicity in the broad plate deformation zones embedded by a number of micro-plates, particularly the controversial Amurian plate. Now the increasingly dense GPS networks in this area provide an important tool to investigate plate tectonic kinematics and to identify the approximate plate tectonic geometries. In this paper, we have processed GPS data (1998-2005) collected by an extensive GPS network (China and South Korea) with more than 85 continuous sites and about 1000 campaign GPS stations. The kinematics of Northeast Asia is studied by modeling GPS-derived velocities with rigid block rotations and elastic deformation. We find that the deformation in Northeast Asia can be well described by a number of rotating blocks, which are independent of the Eurasian plate motion with statistical significance above the $99 \%$ confidence level. The tectonic boundary between the North China and Amuria plates is the Yin Shan-Yan Shan Mountain belts with about $2.4 \mathrm{~mm} / \mathrm{yr}$ extension. Along the boundary between North China and South China, the Qinling-Dabie fault is moving left laterally at about $3.1 \mathrm{~mm} / \mathrm{yr}$. The Amuria and South Korea blocks are extending at about $1.8 \mathrm{~mm} / \mathrm{yr}$. The Baikal Rift between the Amurian and Eurasian plates is spreading at about $3.0 \mathrm{~mm} / \mathrm{yr}$. The $9-17 \mathrm{~mm} / \mathrm{yr}$ relative motion between the Amuria and Okhotsk blocks is accommodated at the East Sea-Japan trench zone. Localized deformation near the Qinling-Dabie fault and Yin Shan-Yan Shan Mountain belts may be elastic strain accumulation due to interseismic locking of faults.
\end{abstract}

(C) 2007 Elsevier B.V. All rights reserved.

Keywords: active tectonics; plate kinematics; Northeast Asia; Amurian plate; GPS

\section{Introduction}

The Northeast Asia region is located in a convergent region of the Eurasian, North American, Pacific and Philippine Sea plates. It is characterized by the subduction of the Pacific and Philippine Sea plates and the north-

\footnotetext{
* Corresponding author. Space Geodesy Division, Korea Astronomy and Space Science Institute, Daejeon 305-348, South Korea. Tel.: +82 428653 241; fax: +82 428615610 .

E-mail addresses: sgjin@kasi.re.kr,sg.jin@yahoo.com (S. Jin).
}

eastward expulsion of the Indian plate [17,32,12,13,10]. Current deformation in Northeast Asia is distributed over a broad area extending from Tibet in the south to the Baikal Rift zone in the north and the Kuril-Japan trench in the east, with some rigid blocks, such as South China, Ordos and north China plain (North China) blocks, and possibly the Amurian plate, embedded in the deforming zone (see Fig. 1). Because of low seismicity and there being no clear geographical boundary except for the Kuril-Japan trench and the Baikal rift zone, it has been difficult to accurately describe the plate tectonics in these 


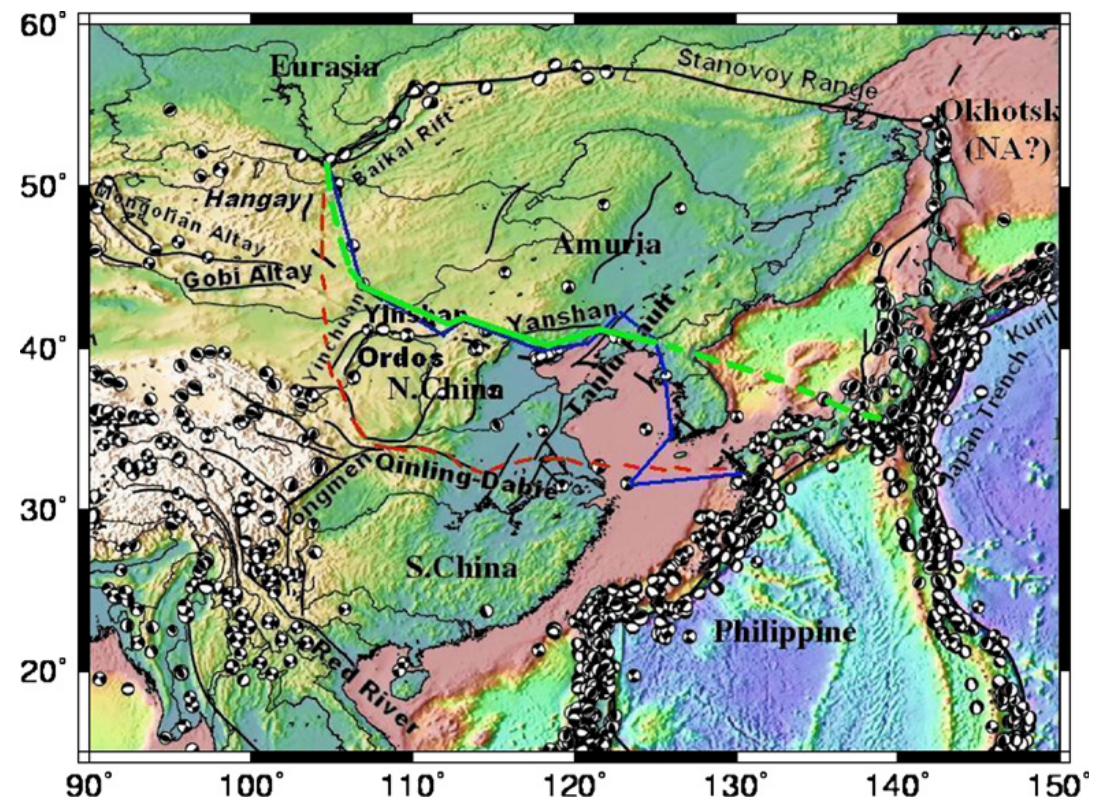

Fig. 1. Tectonics map of Northeast Asia region superimposed on topography. The un-continuous lines are the main fault lines and the dash lines are the undefined plate boundary. Circles are the earthquakes from Harvard CMT catalogue $\left(1976-2005, M_{\mathrm{w}}>5.0\right)$. The upper blue solid line is from Bird [4], the middle black dash boundary line is from Wei and Seno [29], the bottom red dash line is from Heki et al. [9], and the upper green solid + dash lines is this study.

areas. Zonenshan and Savostin [32] first proposed the existence of the Amurian plate based on the clear geographical boundary of the Kuril-Japan trench and the Baikal rift zone, but it becomes diffuse throughout continental Northeast Asia. The proposed Amurian plate (AM) in Northeast Asia is of special interest to constrain the relative motion of the major and minor plate in Northeast Asia and provides a rigorous framework for interpreting seismicity and the kinematics, especially for seismically active Japan. However, the location of the southern boundary of the Amurian plate is poorly understood (see Fig. 1). The upper blue solid line is from Bird [4], the middle black dash boundary line is from Wei and Seno [29], and the bottom red dash line is from Heki et al. [9]. Therefore, the existence of the Amurian plate and its boundary geometry remain subject of contention.

Over the last two decades a number of investigations of the micro-plates tectonics in Northeast Asia have been conducted using geologic, seismological and geodetic data $[32,29,9,23,5,21,2]$. However all of these studies have suffered from limited data quality and quantity, resulting in ambiguous conclusions. For instance, Wei and Seno [29] estimated the AM motion with earthquake slip vectors and their predicted spreading rates of the Baikal Rift are small, with the order of $<1 \mathrm{~mm} / \mathrm{yr}$. Heki et al. [9] assumed that Amuria and North China are regarded as an independent Amurian plate, and estimated spreading rates at the Baikal Rift were about $6 \mathrm{~mm} / \mathrm{yr}$. Steblov et al. [26] used only four GPS sites in or around the AM plate and concluded that AM can neither be resolved nor excluded as a separate plate. Calais et al. [5] postulated that North China (including the possible AM) and South China could be a single rigid block using data from only 9 GPS sites. Apel et al. [2] claimed the existence of the Amurian plate, but still could not determine the location of the southern Amurian plate boundary. These investigations of the tectonics in this region are not conclusive because of the sparse and limited data that were used. Hence, there is much debate surrounding the nature of microplate and its boundaries in Northeast Asia. Attempts to resolve a separate plate have been partly successful $[22,24]$, and the possibility cannot be excluded that a zone of distributed deformation and/or microplates or blocks would better explain some of the seismicity and focal mechanisms in the region. To obtain a more accurate estimate of plate geometry it is necessary to expand the space geodetic observations in this region. In this paper, we present new dense geodetic results for Northeastern Asia by processing data from about 1000 campaign stations and 85 continuous GPS sites in China and South Korea for the period 1998-2005, as well as combining recently published velocities for the Bailkal Rift and Mongolia [5]. The possibility of microplate motion independent of the Eurasian plate is tested using GPS derived velocities and its boundary and kinematics are further discussed. 


\section{GPS data and processing}

In August 1998, the national projects "Crustal Movement Observation Network of China (CMONC) was initiated. The network provides data from a nationwide fiducial network of 25 continuous GPS sites observed from August 1998 to January 2005, and data from 56 survey mode sites with yearly occupations for the period 1998 2005. They also include more than 900 regional campaign stations operated in 1999, 2001, and 2004. All of the sites were observed continuously for at least 4 days during each session. In addition, the Korean GPS Network (KGN) with more than 45 permanent GPS sites was established in 2000 by the Korea Astronomy and Space Science Institute (KASI), the Ministry Of Governmental Administration and Home Affairs (MOGAHA), and the National Geographic Information Institute (NGI). We incorporated 54 core IGS sites that were used for ITRF2000 [1] and permanent IGS sites located in Northeast Asia (Irkutsk (IRKT) in East Russia, Baatar (ULAB) in Mongolia, Daejeon (DAEJ) and Suwon (SUWN) in South Korea, and Shanghai (SHAO), Xi' an (XIAN), Changchun (CHAN), Kunming (KUNM), Lasha (LHAS) and Beijing (BJFS) in China). These GPS sites are shown in Fig. 2. The pentagon ( $\star$ stands for the permanent GPS sites (2000-2005), the dot (-) denotes the campaign GPS sites and the triangle $(\triangle)$ is the yearly observed GPS sites (1999-2005). All available GPS data were processed in single-day solutions using the GAMIT software [15] in a three-step approach. At the first step, loose a-priori constraints were applied to all parameters and double-differenced GPS phase observations from each day were used to estimate station coordinates, the zenith tropospheric delay (ZTD) at each station every $2 \mathrm{~h}$, and the GPS satellite orbital parameters and Earth rotation parameters (ERP). The IGS final orbits, IERS Earth orientation parameters, azimuth- and elevation-dependent antenna phase center models, as recommended by the IGS were used in the data processing. The 54 global IGS stations served as ties to the ITRF2000 frame [1]. At the second step, the regional daily solutions were combined with global solutions produced by the Scripps Orbital and Position Analysis Center (SOPAC, http://sopac.ucsd.edu/) using the GLOBK software [8], and the reference frame was applied to the solution by performing a seven-parameter transformation to align it to ITRF2000 (via the global 54 core stations). At the third step, the site velocities were estimated by least square linear fitting to time variations of the daily coordinates for each station. Thus, the GPS position time series and velocities can be obtained. The $\sim 1000$ GPS site velocity field combining with recently published velocities at the Baikal Rift and Mongolia [5] are shown in Fig. 3 with respect to the Eurasian plate. These solutions for the Chinese mainland are more reliable and more accurate than the results of Wang et al. [28] and Zhang et al. [31] due to the longer observation series (1998-2005). The

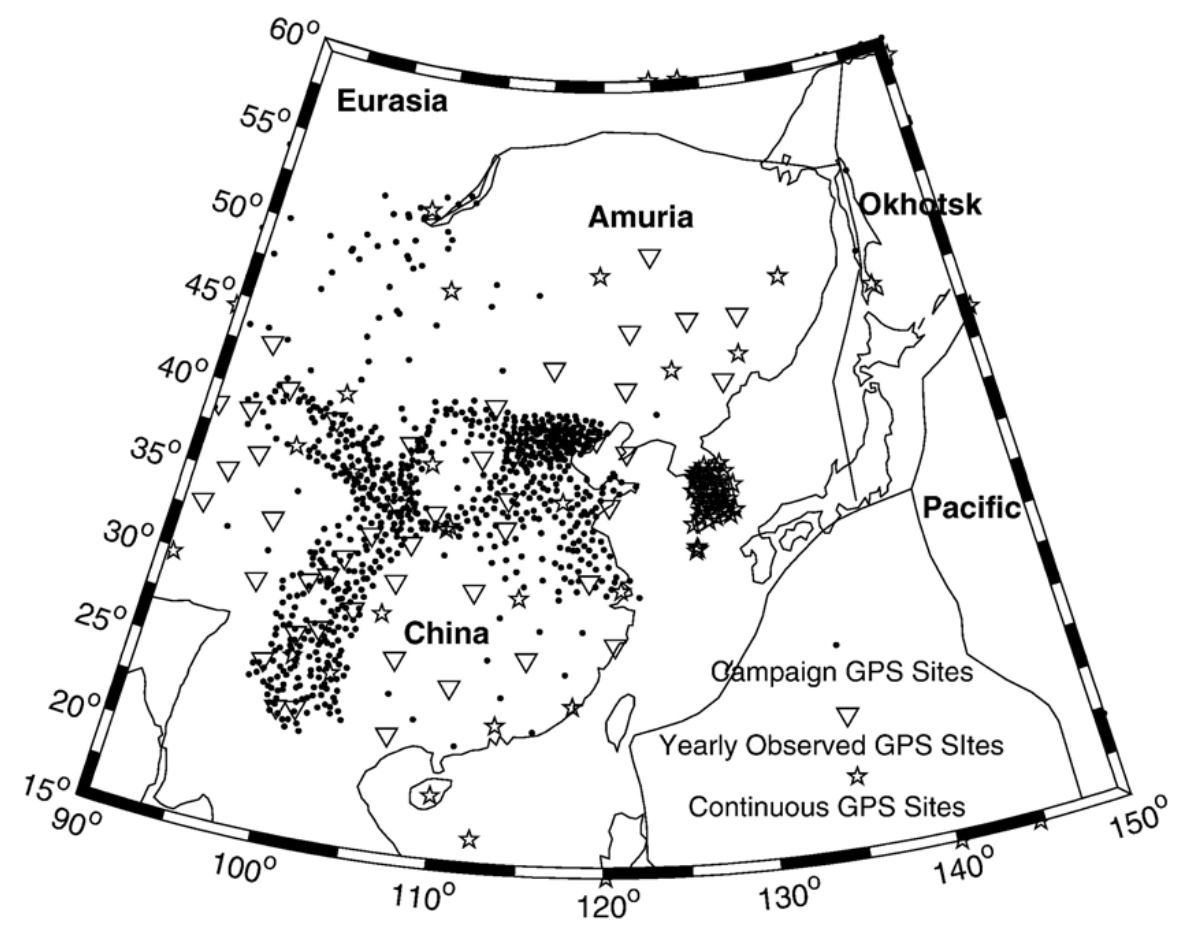

Fig. 2. GPS sites distribution in this study. The pentagon ( $\downarrow)$ is the permanent GPS site, dot $(\mathbf{)})$ is the campaign GPS site and triangle $(\triangle)$ is the yearly observed GPS site. The solid lines are the known plate boundaries. 


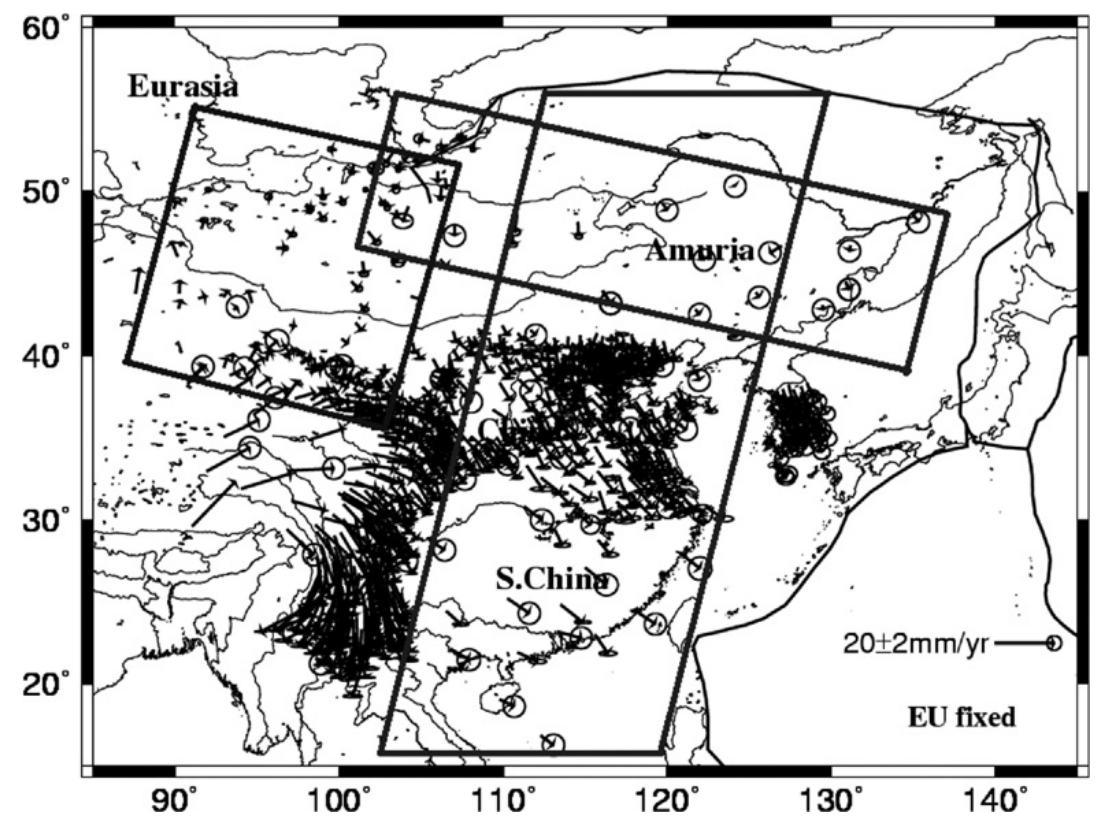

Fig. 3. Horizontal velocities of all used GPS sites and their 95\% confidence ellipses in Eurasia-Fixed reference frame for the period $1998-2005$.

data of Wang et al. [28] and Zhang et al. [31] are mostly for a 2-3 year period (1998-2001).

\section{Method and results}

\subsection{Block modeling method}

The definition of the micro-plate geometries in Northeast Asia is quite unclear, especially their boundaries. Seismic and geodetic data can be used to determine plate boundaries and kinematics. The seismicity distribution gives a snapshot of the deformation. However, sparse seismicity and incomplete catalogues in Northeast Asia limit the accuracy of this method. Space geodetic data can be used to define the plate boundary by testing an independent plate rotation about a best-fit Euler's rotation pole obtained by geodetic velocities. Here we assumed several plates or blocks in NE Asia whose plate boundary geometries were defined principally on the basis of seismicity and faults: EU (Eurasia), AM (Amuria), SK (South Korea), NC (North China), SC (South China), AK $(\mathrm{AM}+\mathrm{SK}), \mathrm{AN}(\mathrm{AK}+\mathrm{NC})$, EA (East Asia) (see Fig. 1). The boundaries are respectively the Yin Shan-Yan Shan Mountain belts for AM-NC, the Qinling-Dabie fault for NC-SC and the Tanlu fault for NC-SK blocks. As GPS data near faults might be affected by elastic strain [27], we define our plates as rigid blocks with dislocations in an elastic half-space, i.e.

$$
v=\Omega \times r+\sum_{f=1}^{N_{\text {faults }}}\left(G^{*} s\right)_{f}
$$

where $v$ is the velocity, $r$ is the position vector, the first term on the right-hand side represents rigid rotation due to the angular velocity $\Omega$ of the block, and the second term (summation term) represents elastic strain related to fault slip near block boundaries due to locking of the faults in the upper crust, convolving a Green's function $G$ response of an Earth model to slip distribution $s$ on each fault. To calculate the elastic contribution to the velocity field, we use Okada's [18] solutions for the surface deformation due to an arbitrarily inclined dislocation in a homogeneous elastic half-space. In order to use these formulas, we project the fault geometry and stations positions from spherical to planar geometry. More detailed descriptions are referred to Meade and Hager [16]. Then the rigid block motion and the elastic strain are modeled simultaneously to estimate the Euler ration parameters of each block (see Table 1). Here only continuously and yearly observed GPS stations are used, such as for the AM plate using the sites (ULAB (ULA1), JB10, JB12, JB13, JB14, JB15, JB17, HLAR, KHAJ, CHAN, and SUIY). In addition, the angular velocity of the Eurasian plate was estimated from the velocities of 22 IGS sites located on the Eurasian plate (TROM, MADR, HERS, BRUS, KOSG, 7203, ZIMM, VILL, OBER, ONSA, WETT, POTS, GOPE, GRAS, BOR1, LAMA, KIRU, JOZE, ZWEN, IRKT, KIT3, KSTU), including the core sites in the Eurasian plate employed for the orientation and maintenance of the ITRF2000 [1] (see Table 1). The horizontal velocities of sites in Europe due to postglacial rebound are relatively small and therefore do not affect the estimates of Euler poles. 
Table 1

Absolute and relative angular velocity vectors for the Eurasian, Amurian, South Korea, North China and South China plates

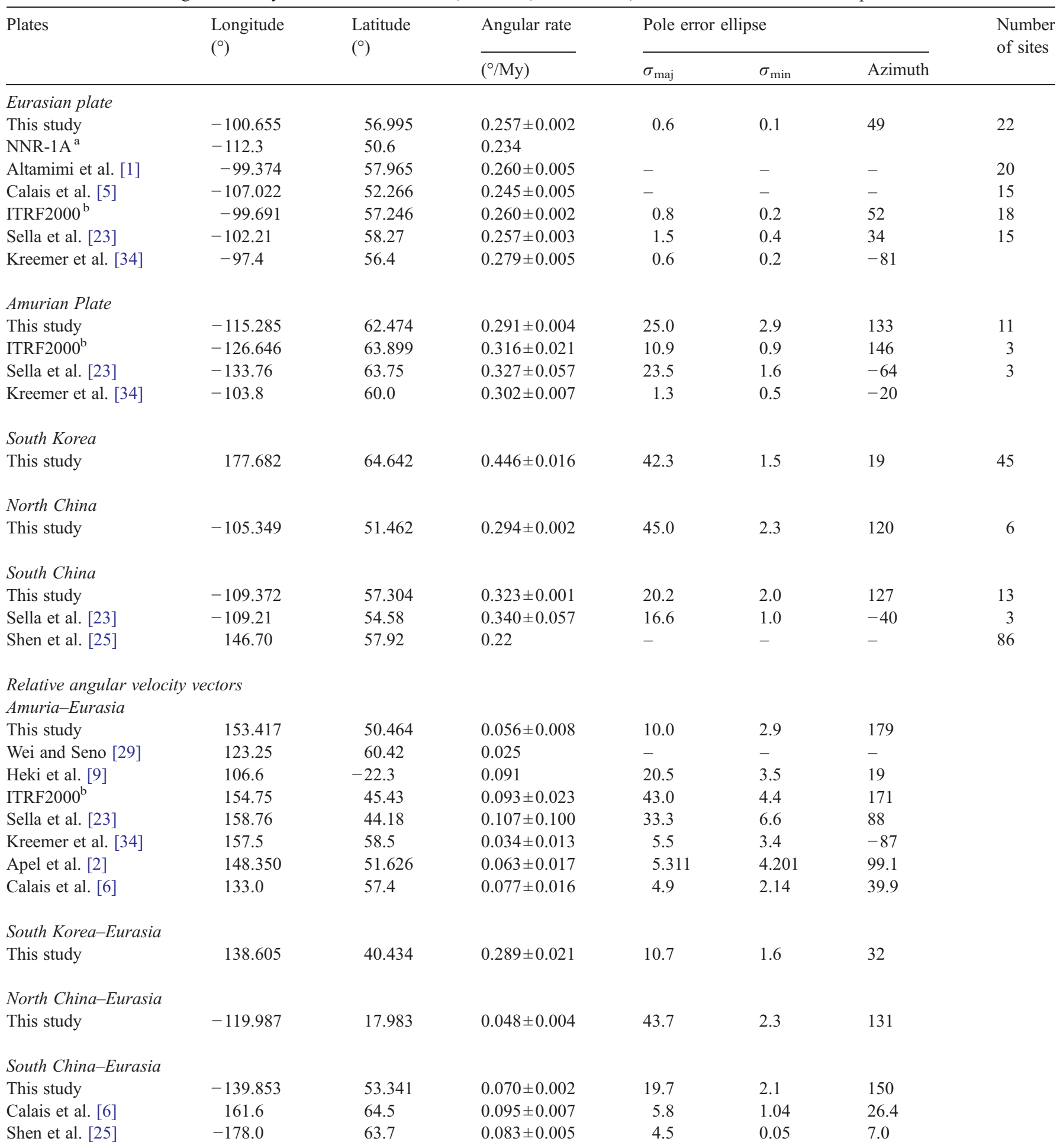

Some previous estimates of the motions of some of these plates are listed for comparison.

Rotation is in a clockwise direction about the pole. The error ellipses of the poles are described by the $1 \sigma$ semi-major and semi-minor axes of each error ellipse and the clockwise angle from true north of the semi-major axis.

${ }^{\mathrm{a}}$ No-Net-Rotation NUVEL-1A (NNR-1A) model [7].

b Angular velocity vectors were estimated from $12 \mathrm{yr}$ of CGPS in ITRF2000 [33]. 
We subtracted the Eurasia-ITRF2000 rotation estimated here from the ITRF2000 velocities to map our results into the Eurasia-fixed reference frame (Fig. 3).

\subsection{Testing results}

To test whether the microblocks are independent of the Eurasian plate, we used a $\chi^{2}$ test that compares how well two different models fit a set of data. $\chi^{2}$ is a sum of the squares of weighted residuals defined as:

$\chi^{2}=\sum_{i=1}^{N} \frac{\left(v_{\mathrm{o}}(i)-v_{\mathrm{m}}(i)\right)^{2}}{\sigma_{\mathrm{o}}^{2}(i)}$,

where $v_{\mathrm{o}}(i)$ is the observation velocity of site $i, v_{\mathrm{m}}(i)$ is the calculated velocity of site $i$ from the plate rotation model, $\sigma_{\mathrm{o}}^{2}(i)$ is the variance of observation velocity in site $i$, and $N$ is the total number of observations. Table 2 shows the $\chi^{2}$ for each model. The $\chi^{2}$ for the model of independent AM, SK, SC, NC blocks is smaller than the Eurasian plate and a 2-block model (EU and EA), respectively. To check whether AM, SK, SC and NC are independent blocks, we perform an $F$-ratio statistical test.

First, we assume the one-block model in which East Asia (EA) is part of the Eurasian plate and the two-block model in which the East Asia (EA) plate rotates independently with respect to the Eurasian plate (EU). The 3-block model assumes that the EA is divided into the AN (Amuria+South Korea + North China) and South China (SC) plates, while the 4-block model contains the EU, SC (S.China), NC (N.China) and AK (Amuria+S.Korea) plates. The 5-block model is the EU, SC, NC, AM and SK plates. These blocks were defined principally on the basis of seismicity and faults (see Fig. 1). We

Table 2

Statistic tests of different block models

\begin{tabular}{llllr}
\hline Number of blocks $^{\text {a }}$ & \multicolumn{1}{l}{$\chi^{2}$} & $\chi_{f}^{2}$ & $f$ & \multicolumn{1}{l}{$F$} \\
\hline 1 & 5904.8 & 6.4 & 922 & \\
2 & 1295.4 & 1.4 & 939 & 1086.5 \\
3 & 1221.2 & 1.3 & 936 & 18.5 \\
4 & 1191.5 & 1.3 & 933 & 7.6 \\
5 & 980.5 & 1.1 & 930 & 65.0 \\
6 & 976.7 & 1.1 & 927 & 1.2 \\
\hline
\end{tabular}

${ }^{\text {a } 1: ~ E U ~(E u r a s i a) ; ~ 2: ~ E U ~ a n d ~ E A ~(E a s t ~ A s i a) ; ~ 3: ~ E U, ~ A N ~(A m u r i a+~}$ South Korea+North China) and SC (South China); 4: EU, AK (Amuria+S.Korea), NC, SC; 5: EU, NC, SC, AM and SK; 6: EU, NC, SC, SK, West AM and East AM. $f$ is the number of degrees of freedom and $\chi_{f}^{2}$ is the reduced $\chi^{2}$ as the ratio of $\chi^{2}$ to $f$.

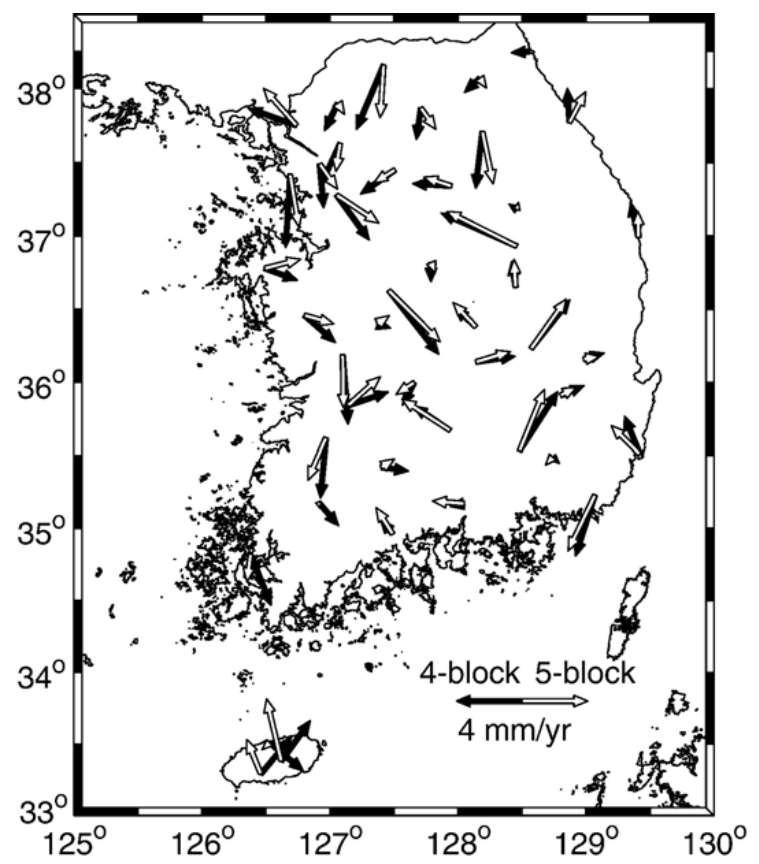

Fig. 4. Residual velocities (observed minus predicted) in South Korea from the 4- and 5-block models. Residual velocities from the 4-plate model (EU, SC, NC, and $\mathrm{AK}(\mathrm{AM}+\mathrm{SK})$ ) are shown in black; residuals from the 5-plate model (EU, SC, NC, AM and SK) are shown in white. Residuals are reduced with additional independently rotating South Korea block.

compare the misfit of each model inversion and test for significance using the $F$-ratio [35]:

$F=\frac{\left[\chi^{2}(1 \text { block })-\chi^{2}(2 \text { block })\right] / 3}{\chi^{2}(2 \text { block }) /(N-3)}$,

In Table 2 one can clearly see that for the two-block model (EU and EA) the reduced chi-squared misfit of GPS velocity observations has been greatly reduced from 6.4 (for the one-block model (EU +EA)) to 1.4 (for the two-block model (EU and EA)) and the $F$-ratio statistic (Eq. (2)) is 1086.5, which is well above the $99 \%$ confidence level of 3.8. The reduced chi-squared misfits of other independently rotating blocks for the 3-block, 4-block and 5-block models are also greatly degraded, and the calculated $F$-statistics between the 2-3 block and 3-4 block models are well above the $99 \%$ confidence level of 3.8 as well as between the 3-4 block and $4-5$ block models. Due to the Tanlu fault crossing the AM plate, we have divided the AM into the West $\mathrm{AM}$ and East AM blocks. The test result shows that the reduced chi-squared misfit is nearly the same and the $F$-statistic between the 5-block and 6-block models is well below the $99 \%$ confidence level of 3.8. These results indicate that the $\mathrm{AM}, \mathrm{SK}, \mathrm{NC}$ and $\mathrm{NC}$ are 
independent of the Eurasian plate motion. Furthermore, it shows that the South Korea block (SK) is excluded from the Amurian plate (AM), coinciding with recent test results using fewer GPS sites [11]. Fig. 4 shows residual velocities (observed minus predicted) in South Korea from the 4- and 5-block models. Residual velocities from the 4-plate model (EU, SC, $\mathrm{NC}$, and $\mathrm{AK}(\mathrm{AM}+\mathrm{SK}))$ are shown in black and residuals from the 5-plate model (EU, $\mathrm{SC}, \mathrm{NC}, \mathrm{AM}$ and SK) are shown in white. It has been seen that residuals are reduced with additional independently rotating South Korea block. Moreover, a further test to determine whether South Korea belongs to the North China block gives an $F$-ratio statistic of 26.4, which is well above the $99 \%$ confidence level value of 3.8 , indicating that South Korea does not reside on the North China plate. The South Korea block is independent of the $\mathrm{AM}, \mathrm{NC}$ and SC blocks motion, which is possibly subject to the westward subduction of the Philippine Sea and Pacific plates. In addition, the relative angular velocity vectors for independent AM, SK, SC and NC blocks with respect to the EU plate are further obtained in Table 1, which describe relative motions of plate pairs. For example, the relative angular velocity vector the AMEU plate has a rotation rate of $0.056 \pm 0.008^{\circ} / \mathrm{Ma}$ at the pole of $153.417^{\circ} \mathrm{E}$ and $50.464^{\circ} \mathrm{N}$.

\section{Discussion}

As the main $\mathrm{E}-\mathrm{W}$ trending tectonic lines in East China are the Qinling-Dabie fault and Yin Shan-Yan

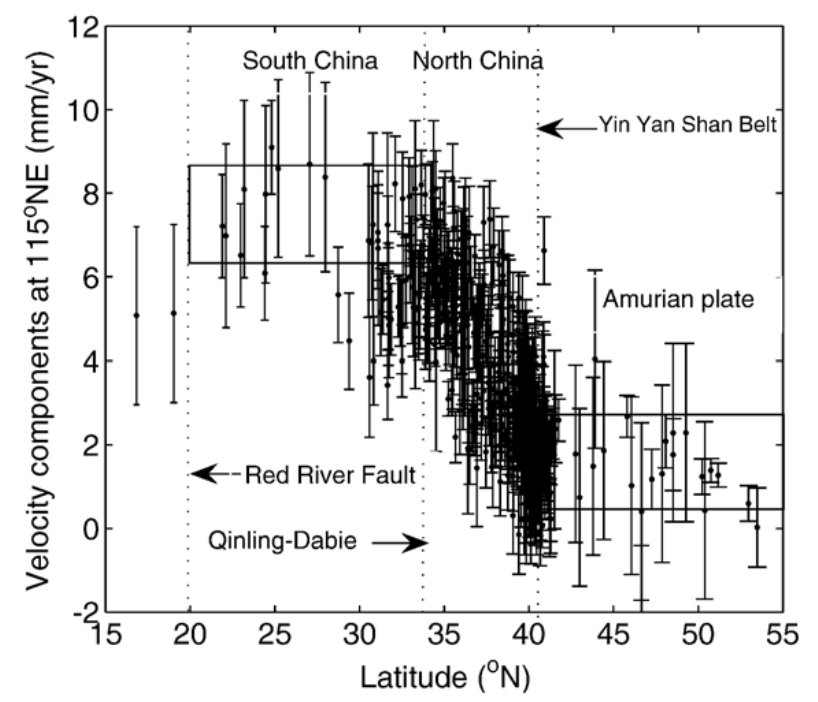

Fig. 5. The fault-parallel velocity component distribution with latitude. The velocities of GPS sites for the longitude $107^{\circ}-135^{\circ}$ (seeing the swath box in Fig. 3) were projected into the faults and mountain belts parallel direction component (about $\mathrm{N} 115^{\circ} \mathrm{E}$ ). This component distribution shows the fault-parallel velocity gradient with the latitude.
Shan Mountain belts at about $\mathrm{N} 115^{\circ} \mathrm{E}$, we project the GPS velocities in the direction parallel to the strike of faults and mountain belts (about $\mathrm{N} 115^{\circ} \mathrm{E}$ ) at longitude $107^{\circ}-135^{\circ}$ (within swath box in Fig. 3) after removing the predicted motion of the Eurasian plate. The N-S velocity gradient appears clearly in the fault parallel velocity components (Fig. 5). The spatial variation in fault-parallel velocity indicates strain accumulations in the Qinling-Dabie fault and Yin Shan-Yan Shan Mountain belts. Fig. 6 shows the horizontal velocities of GPS sites and their 95\% confidence ellipses in the South China plate-fixed reference frame. It has also reflected obvious difference motions between Amuria, North China and South China blocks spanning 100$135^{\circ} \mathrm{E}$ and $25-50^{\circ} \mathrm{N}$. West of Mongolia (Hangay) the velocities appear to be directed northward, with rates decreasing and then increasing from south to north, converging at the Altay and diverging at the Baikal Rift, up to the west Mongolian Altay (Fig. 3). Thus, the southwest boundary of the AM block possibly runs from the west Baikal Rift to Mongolian Altay, Gobi Altay, Yin Shan-Yan Shan Mountain belts, over South Korea and through to Japan, shown in Fig. 1 with decided solid line and postulated dash line (green). GPS velocities in central-west Asia show a complex deformation in the eastern Tibet margin, Sichuan and Yunnan (Fig. 3). It leads to a right-lateral rotation motion due to the northeastward expulsion of the Indian plate, forming a complex distributed faulting and deformation belt [25]. A further analysis with several sub-blocks shows that these sites along the eastern Tibet margin, Sichuan and Yunnan didn't impact our statistical analysis of blocks in Northeast Asia.

The residual velocities (observed minus estimated) with respect to its preferred block are shown in Fig. 7, which indicate where the model matches the observed velocities. The residual velocities are on the order of $1.0 \mathrm{~mm} / \mathrm{yr}$ in the SC, $1.1 \mathrm{~mm} / \mathrm{yr}$ in the AM and $1.2 \mathrm{~mm} /$ $\mathrm{yr}$ in the SK, indicating that the AM, SK and SC are almost rigid blocks. However, larger residual velocities on order of $1.6 \mathrm{~mm} / \mathrm{yr}$ are found in the $\mathrm{NC}$, indicating un-modeled deformation, especially in block boundaries, Qinling-Dabie Fault and Yin Shan-Yan Shan Mountain belts. The estimated relative motions along the block boundaries are shown in Fig. 8, where arrows denote the spreading or converging rates and the solid lines without arrows are the earthquake slip vector directions along these boundaries. The GPS-derived relative motion directions are nearly the same as the earthquake slip vector directions. However there is a small discrepancy at Baikal Rift. It may be due to the larger uncertainty of earthquake slip vectors $\left( \pm 15^{\circ}\right)$. 


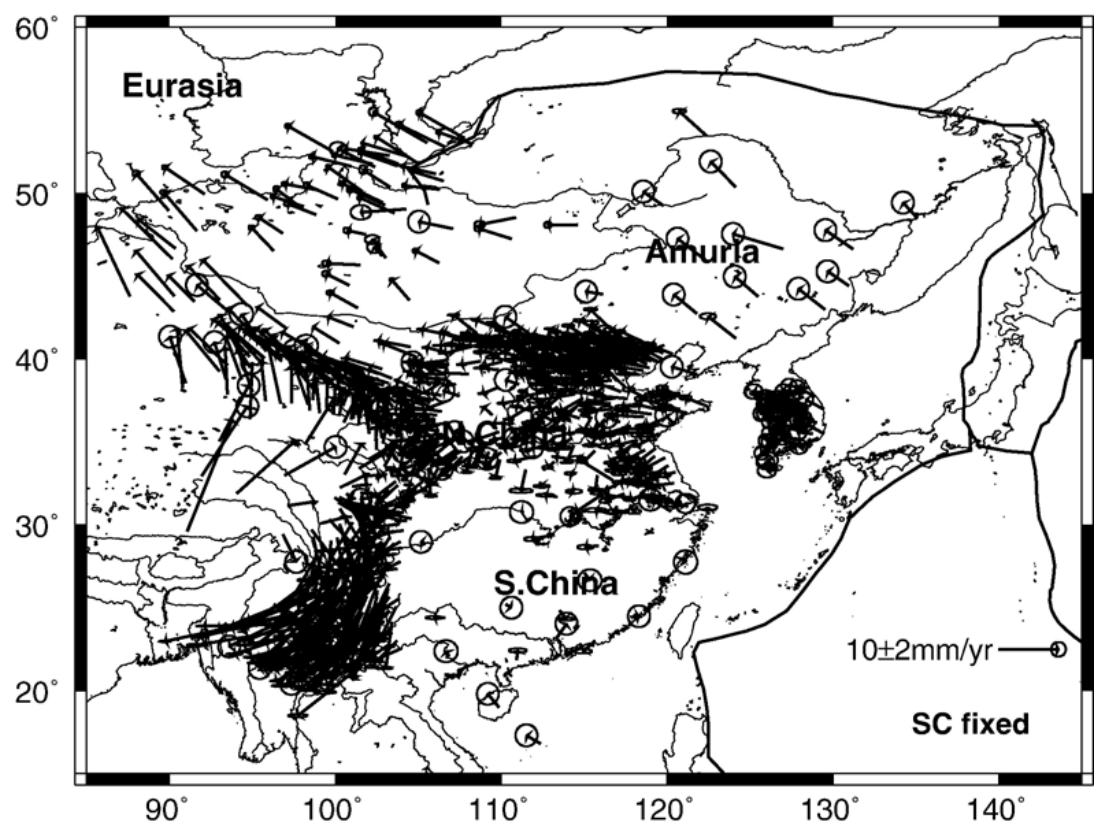

Fig. 6. Horizontal velocities of GPS sites and their $95 \%$ confidence ellipses in the South China plate-fixed reference frame.

Another is possibly the Euler vector problem of the large non-rigid Eurasian plate (EU). For instance, Table 1 lists different Euler vectors of the Eurasian plate, and larger discrepancy is found between Calais et al. [5] and other geodetic results. The tectonic boundaries between the
North China and Amuria plates, the Yin Shan-Yan Shan Mountain belts, are extending at about $2.4 \mathrm{~mm} / \mathrm{yr}$. The Qinling-Dabie fault between the North China and South China plates is moving left laterally at about $3.1 \mathrm{~mm} / \mathrm{yr}$. This difference between Amuria and South China

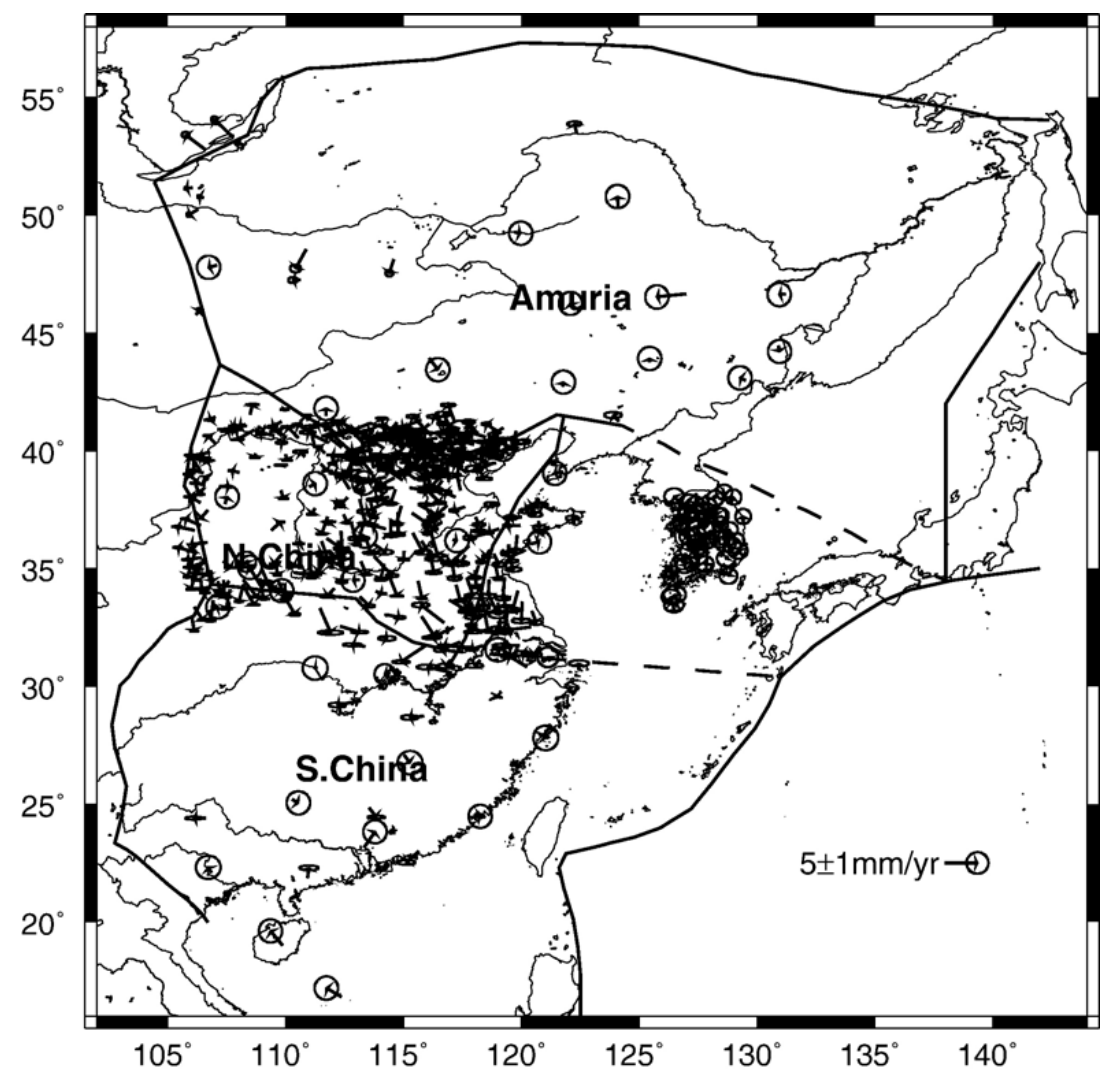

Fig. 7. Residual velocities of each sites (observed minus predicted) with respect to its preferred block. 


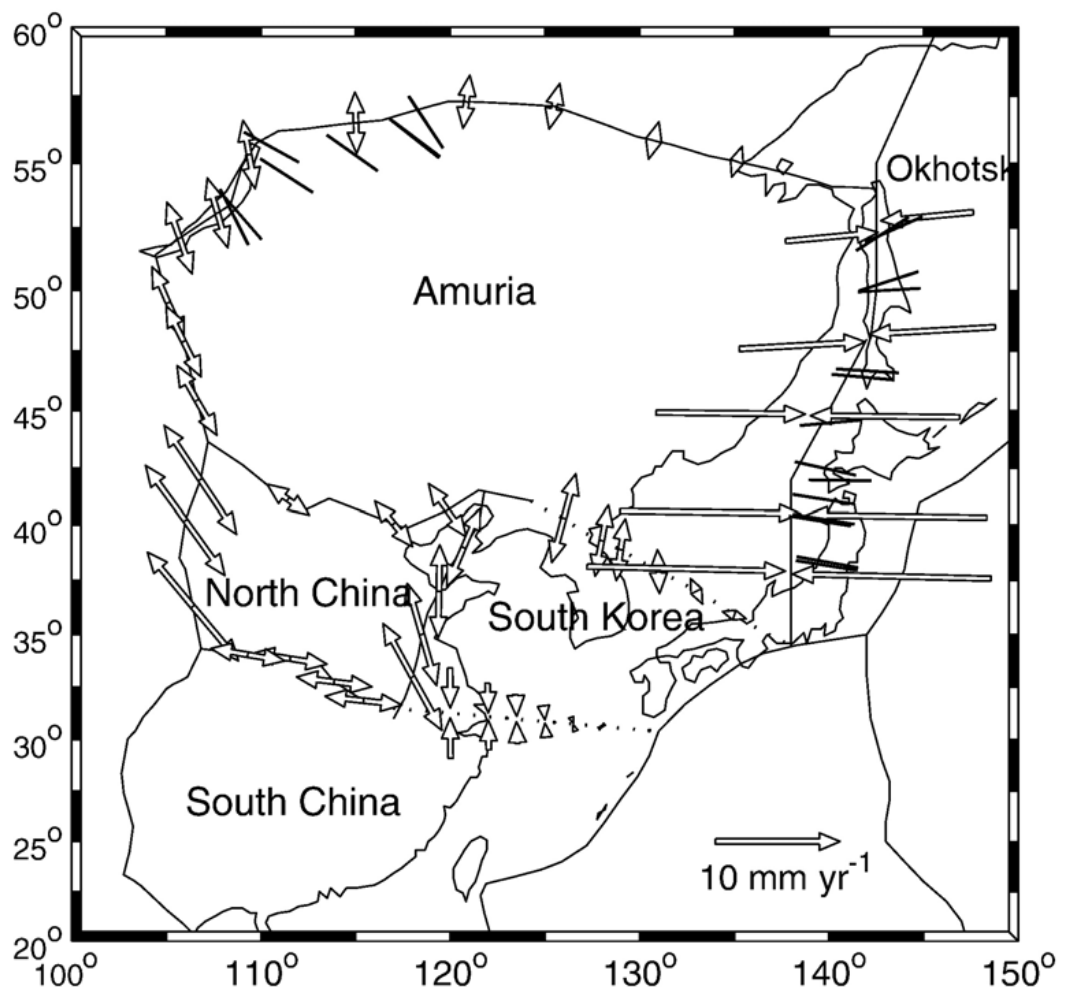

Fig. 8. Relative motions at plate boundaries. The arrows denote the spreading or converging rates and the solid lines without arrows are earthquake slip vector directions along these boundaries.

predicted rates is about $5.5 \mathrm{~mm} / \mathrm{yr}$, almost consistent with geological results by Peltzer and Tapponnier [20], Avouac and Tapponnier [3] and Peltzer and Saucier [19]. The Tanlu fault between the North China and South Korea blocks is moving right laterally at about $3.8 \mathrm{~mm} / \mathrm{yr}$. The Amuria and South Korea blocks are

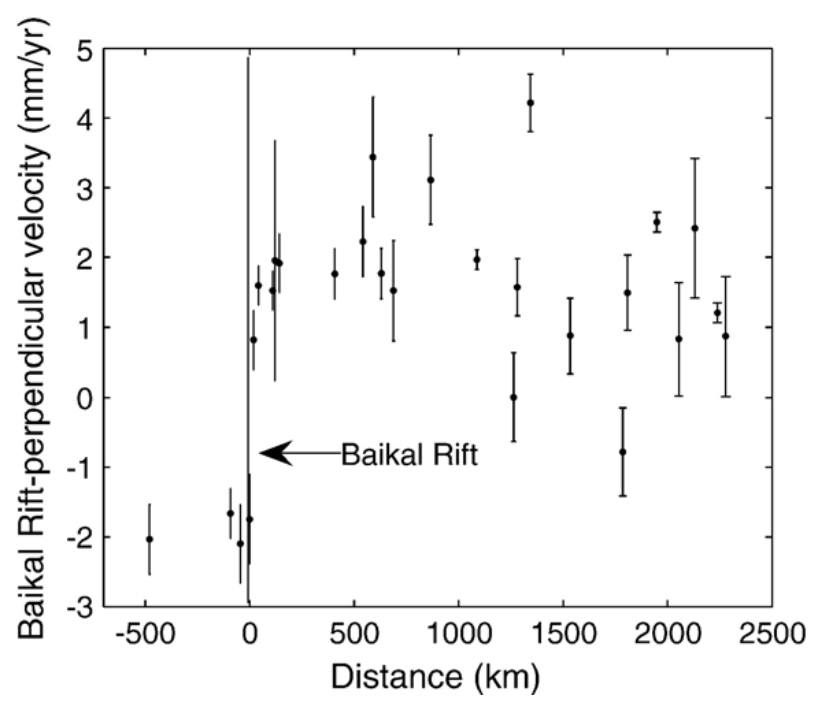

Fig. 9. Baikal Rift-perpendicular velocities on a $55^{\circ} \mathrm{NE}$ profile. The horizontal axis is the distance from the Baikal Rift. Black dots are the GPS velocities and associated $95 \%$ confidence error bars. extending at about $1.8 \mathrm{~mm} / \mathrm{yr}$. The convergent rates at the boundaries of the AM and Okhotsk [2] are from 9 to $17 \mathrm{~mm} / \mathrm{yr}$, similar to the seismic results of Kogan et al. [14]. The spreading rates in the Baikal Rift zone are about $3.0 \pm 1.0 \mathrm{~mm} / \mathrm{yr}$, consistent with Calais et al. [5] at $4 \pm 1 \mathrm{~mm} / \mathrm{yr}$ and the GPS-derived average spreading velocities from the GPS observed Baikal Rift-perpendicular velocities at average $3.0 \mathrm{~mm} / \mathrm{yr}$ (see Fig. 9). The

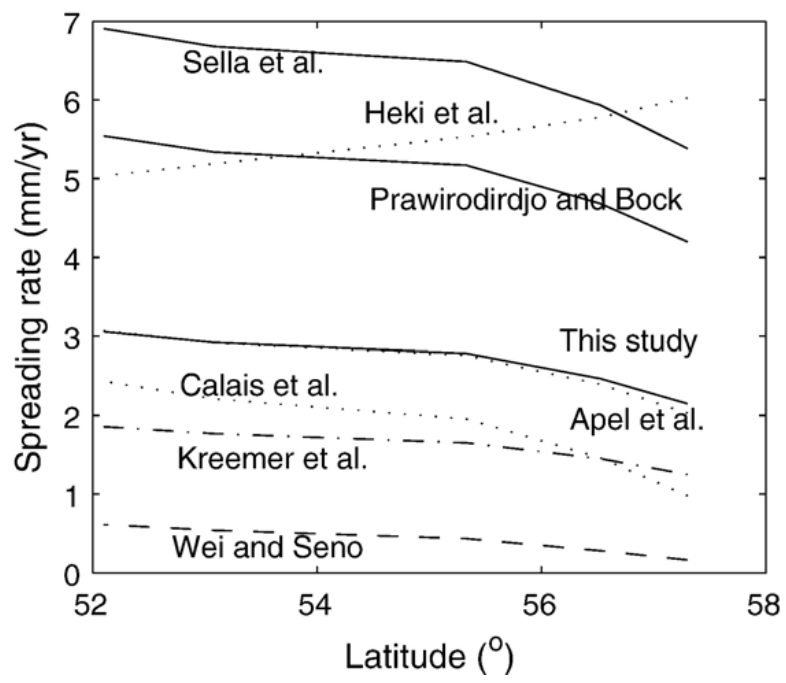

Fig. 10. Comparison of spreading rates at the Baikal Rift. 
used GPS data in the Baikal Rift-Amuria area are shown in the swath box of Fig. 3. Fig. 10 shows a comparison of spreading rates at the Baikal Rift between different AM-EU models. It can be seen that our model estimation is almost consistent with the Apel et al.'s [2] due to using the same GPS data in Amuria excluding two different sites in South Korea. Furthermore, both results are the closest to the GPS-observed spreading velocities, but there is a larger difference with Calais et al.'s [6] as Amuria and North China are regarded as one single rigid block.

\section{Conclusions}

GPS data (1998-2005) from more than 85 continuous and about 1000 campaign stations in Northeast Asia have been processed. The kinematics of Northeast Asia is studied by modeling GPS-derived velocities with rigid block rotations and elastic deformation. It has been found that the deformation in Northeast Asia can be well described by a number of rotating blocks, which are independent of the Eurasian plate motion with statistical significance above the $99 \%$ confidence level. The tectonic boundary between the North China and Amuria plates is the Yin Shan-Yan Shan Mountain belts with about $2.4 \mathrm{~mm} / \mathrm{yr}$ extension. The boundary between North China and South China is the Qinling-Dabie fault, moving left laterally at about $3.1 \mathrm{~mm} / \mathrm{yr}$. The Amuria and South Korea blocks are extending at about $1.8 \mathrm{~mm} / \mathrm{yr}$. The Baikal Rift between the Amurian and Eurasian plates is spreading at about $3.0 \mathrm{~mm} / \mathrm{yr}$. The 9$17 \mathrm{~mm} / \mathrm{yr}$ relative motion between the Amuria and Okhotsk blocks is accommodated at the East Sea-Japan trench zone. Furthermore, the relative motion rates and deformation types are nearly consistent with seismic and geological solutions along their boundaries. In addition, the AM, SK and SC blocks are almost rigid with residual velocities on order of $1.0-1.2 \mathrm{~mm} / \mathrm{yr}$, while the $\mathrm{NC}$ block has larger residual velocities on order of $1.6 \mathrm{~mm} / \mathrm{yr}$, indicating un-modeled deformation in block boundaries. Localized deformation near the QinlingDabie fault and Yin Shan-Yan Shan Mountain belts may be elastic strain accumulation due to interseismic locking of faults.

\section{Acknowledgements}

Figures were made with the public domain software GMT [30]. We are grateful to those who created the Crustal Motion Observation Network of China and made the observation data available. We thank T. Kato, $\mathrm{H}$. Xu, X. Xiong et al. for significant discussions before the manuscript. We also thank C. DeMets for constructive comments and valuable suggestions as well as reviews by R. Burgmann, K. Heki and anonymous. This work was supported by the Korean Ministry of Science and Technology under grants M6-0404.

\section{References}

[1] Z. Altamimi, P. Sillard, C. Boucher, ITRF2000: a new release of the international terrestrial reference frame for earth science applications, J. Geophys. Res. 107 (B10) (2002) 2214, doi:10.1029/ 2001JB000561.

[2] E.V. Apel, R. Burgmann, G. Steblov, N. Vasilenko, R. King, A. Prytkov, Independent active microplate tectonics of northeast Asia from GPS velocities and block modeling, Geophys. Res. Lett. 33 (2006) L11303, doi:10.1029/2006GL026077.

[3] J.P. Avouac, P. Tapponnier, Kinematic model of deformation in central Asia, Geophys. Res. Lett. 20 (1993) 895-898.

[4] P. Bird, An updated digital model of plate boundaries, Geochem. Geophys. Geosyst. 4 (3) (2003) 1027, doi:10.1029/2001GC000252.

[5] E. Calais, M. Vergnolle, V. San'kov, A. Lukhnev, A. Miroshnitchenko, S. Amarjargal, J. Déverchère, GPS measurements of crustal deformation in the Baikal-Mongolia area (1994-2002): implications for current kinematics of Asia, J. Geophys. Res. 108 (B10) (2003) 2501, doi:10.1029/2002JB002373.

[6] E. Calais, L. Dong, M. Wang, Z. Shen, M. Vergnolle, Continental deformation in Asia from a combined GPS solution, Geophys. Res. Lett. 33 (2006) L24319, doi:10.1029/2006GL028433.

[7] C. DeMets, D.F. Argus, R.G. Gordon, et al., Current plate motions, Geophys. J. Int. 101 (1990) 425-478.

[8] A. Herring, GLOBK Global Kalman Filter VLBI and GPS Analysis Program, Version 10.0, Mass. Inst. of Technol., Cambridge, Mass., 2002.

[9] K. Heki, S. Miyazaki, H. Takahashi, M. Kasahara, F. Kimata, S. Miura, K. An, The Amurian plate motion and current plate kinematics in East Asia, J. Geophys. Res. 104 (1999) 29147-29155.

[10] S.G. Jin, P.H. Park, Strain accumulation in South Korean peninsula inferred from GPS measurements, Earth Planets Space 58 (5) (2006) 529-534.

[11] S.G. Jin, P.H. Park, Does the Southern Korean Peninsula belong to the Amurian plate? GPS observations, Stud. Geophys. Geod. 50 (4) (2006) 633-644.

[12] T. Kato, Y. Kaotake, S. Nakao, Initial results from WING, the continuous GPS network in the western Pacific area, Geophys. Res. Lett. 125 (3) (1998) 369-372.

[13] M.G. Kogan, G.M. Steblov, R.W. King, T.A. Herring, D.L. Frolov, S.G. Egorov, V.Y. Levin, A. Jones, Geodetic constrains on the rigidity and relative motion of Eurasian and North American, Geophys. Res. Lett. 27 (2000) 2041-2044.

[14] M.G. Kogan, R. Bürgmann, N.F. Vasilenko, C.H. Scholz, R.W. King, A.I. Ivashchenko, D.I. Frolov, G.M. Steblov, Ch.U. Kim, S.G. Egorov, The $2000 \mathrm{Mw} 6.8$ Uglegorsk earthquake and regional plate boundary deformation of Sakhalin from geodetic data, Geophys. Res. Lett. 30 (3) (2003) 1102, doi:10.1029/2002GL016399.

[15] R.W. King, Y. Bock, Documentation for the GAMIT GPS Analysis Software, Mass. Inst. of Technol., Cambridge, Mass., 2002.

[16] B.J. Meade, B.H. Hager, Block models of crustal motion in southern California constrained by GPS measurements, J. Geophys. Res. 110 (2005) B03403, doi:10.1029/2004JB003209. 
[17] P. Molnar, P. Tapponnier, Cenozoic tectonic of Asia: effects of a continental collision, Science 189 (1975) 419-426.

[18] Y. Okada, Surface deformation due to shear and tensile faults in a half space, Bull. Seismol. Soc. Am. 75 (1985) 1135-1154.

[19] G. Peltzer, F. Saucier, Present-day kinematics of Asia derived from geologic fault rates, J. Geophys. Res. 101 (1996) 27,943-27,956.

[20] G. Peltzer, P. Tapponnier, Formation and evolution of strike-slip faults, rifts, and basins during the India-Asia collision: an experimental approach, J. Geophys. Res. 93 (1998) 15,085-15,117.

[21] C. Petit, M. Fournier, Present-day velocity and stress fields of the Amurian plate from thin-shell finite-element modelling, Geophysics. J. Int. 160 (2005) 357-369.

[22] S. Riegel, K. Fujita, B. Koz'min, V. Imaev, D. Cook, Extrusion tectonics of the Okhotsk plate, northeast Asia, Geophys. Res. Lett. 20 (1993) 607-610.

[23] G.F. Sella, T.H. Dixon, A. Mao, REVEL: a model for recent plate velocities from space geodesy, J. Geophys. Res. 107 (B4) (2002) (ETG11-1-32).

[24] T. Seno, T. Sakurai, S. Stein, Can the Okhotsk plate be discriminated from the North American plate? J. Geophys. Res. 101 (1996) 11,305-11,315.

[25] Z.-K. Shen, J. Lü, M. Wang, R. Bürgmann, Contemporary crustal deformation around the southeast borderland of the Tibetan Plateau, J. Geophys. Res. 110 (2005) B11409, doi:10.1029/2004JB003421.

[26] G.M. Steblov, M.G. Kogan, R.W. King, C.H. Scholz, R. Bürgmann, D.I. Frolov, Imprint of the North American plate in Siberia revealed by GPS, Geophys. Res. Lett. 30 (18) (2003) 1924, doi:10.1029/2003GL017805.
[27] W. Thatcher, Microplate model for the present-day deformation of Tibet, J. Geophys. Res. 112 (2007) B01401, doi:10.1029/ 2005 JB004244.

[28] Q. Wang, P. Zhang, J.T. Freymueller, R. Bilham, K.M. Larson, X. Lai, X.Z. You, Z. Niu, J. Wu, Y. Li, J. Liu, Z. Yang, Q. Chen, Present-day crustal deformation in China constrained by Global Positioning System measurements, Science 294 (2001) 574-577.

[29] D. Wei, T. Seno, Determination of the Amurian plate motion, in: M. Flower, S. Chung, C. Lo, T. Lee (Eds.), Mantle Dynamics and Plate Interaction in East Asia, 1998, pp. 337-346.

[30] P. Wessel, W.H.F Smith, New, improved version of Generic Mapping Tools released: Eos, Trans. Am. Geophys. Union 79 (1998) 579.

[31] P. Zhang, Z. Shen, M. Wang, W.J. Gan, R. Burgmann, P. Molnar, Continuous deformation of the Tibetan Plateau from global positioning system data, Geology 32 (9) (2004) 809-812.

[32] L.P. Zonenshain, L.A. Savostin, Geodynamics of the Baikal rift zone and plate tectonics of Asia, Tectonophysics 76 (1981) 1-45.

[33] L. Prawirodirdjo, Y. Bock, Instantaneous global plate motion model from 12 years of continuous GPS observations, J. Geophys. Res. 109 (2004) B08405, doi:10.1029/2003JB002944.

[34] C. Kreemer, W.E. Holt, A. Haines, An integrated global model of present-day plate motions and plate boundary deformation, Geophys. J. Int. (2003) 8-34.

[35] S. Stein, R. Gordon, Statistical tests of additional plate boundaries from plate motion inversions, Earth Planet. Sci. lett. 69 (1984) 401-412. 